$$
\begin{array}{r}
\text { IMPLICAÇ } \\
\text { BIOÉTICAS } \\
\text { GENOCÍDIO: ANS } \\
\text { CRÍTICO } \\
\text { COLONIALID } \\
\text { POR UMA BIOÉT } \\
\text { DA ALTERA }
\end{array}
$$




\section{IMPLICAÇÕES BIOÉTICAS DO GENOCÍDIO: ANSEIOS CRÍTICOS DA COLONIALIDADE POR UMA BIOÉTICA DA ALTERAÇÃO}

\section{JOÃO VINICIUS MARQUES}

Programa de PÓS-GraduAÇÃo EM SOCIOlOGia E ANTropologia dA UFPA (PPGSA/UFPA) 


\title{
IMPLICAÇÕES BIOÉTICAS DO GENOCÍDIO: ANSEIOS CRÍTICOS DA COLONIALIDADE POR UMA BIOÉTICA DA ALTERAÇÃO
}

\section{Resumo}

Este trabalho tem como caso a relação entre a bioética e o crime de genocídio no horizonte dos marcos de proteção a atentados aos direitos humanos. Seu propósito é colocar em perspectiva suas delimitações conceituais e históricas. Em seu argumento, sinaliza a necessidade de alteração dos pactos de proteção e defesa da vida, aqui esboçado como bioética de alteração, tomando por referência contribuições intelectuais dos estudos de raça e dos estudos cultuais e feminismos descoloniais.

Palavras-chave: Bioética, genocídio, descolonização.

\section{BIOETHICAL IMPLICATIONS OF GENOCIDE: CRITICAL AN- XIETIES OF COLONIALITY FOR A BIOETHICS OF CHANGE}

\begin{abstract}
This paper deals with the relationship between bioethics and the crime of genocide within the framework of the protection of human rights violation. The purpose of this paper is to put into perspective its conceptual and historical delimitations. In the argument, it points out the need to change the covenants of protection and defense of life, outlined here as bioethics of change, taking as reference intellectual contributions from studies of race and from studies of cults and decolonial feminisms.

Keywords: Bioethics, genocide, decolonization.
\end{abstract}




\section{IMPLICACIONES BIOÉTICAS DEL GENOCIDIO: ANSIAS CRÍTICAS DE LA COLONIALIDAD POR UNA BIOÉTICA DE LA ALTERACIÓN}

\section{Resumen}

Este trabajo aborda la relación entre la bioética y el crimen de genocidio en el horizonte de los marcos de protección contra ofensas a los derechos humanos. Su propósito es poner en perspectiva sus delimitaciones conceptuales e históricas. En su argumento, señala la necesidad de alteración de los pactos de protección y defensa de la vida, delimitados aquí como bioética de alteración, tomando como referencia las contribuciones intelectuales de los estudios sobre raza, de los estudios culturales y los feminismos decoloniales.

Palabras clave: Bioética, genocidio, descolonización.

João Vinicius Marques

marques.jvinicius@gmail.com 


\section{INTRODUÇÃO}

O texto que segue é um estudo de caso do que proponho como uma bioética de alteração. Entendo que a bioética de alteração que aqui sugiro se refere à necessidade de reconhecermos a incompatibilidade de um projeto ético de respeito e defesa da vida com o que hoje se encontra estruturalmente projetado para subjugar a sua diferença de si, chamado e reduzido nessa perspectiva de o Outro, nos usos e discursos da modernidade científica e ocidental.

O caso da inter-relação sistemática da bioética e da prevenção aos crimes de genocídio representa bem essa incompatibilidade: a forma como os interesses e delimitações das fronteiras da bioética e do genocídio reduzem os horizontes desses conceitos às figuras modernas da individualização e da fragmentação epistêmica, que nos impede, por conseguinte, de enxergarmos mais concretamente os seus laços e conexões internas para a consciência ética necessária de alteração da realidade dada. Sim, alteração, porque a realidade operante não nos permite pensar a mitigação das mortes e das dinâmicas de sufocamento e deterioração das vidas hoje relegadas à diversidade e à alteridade. A mitigação como propósito para o projeto de uma alteração também decorre da constatação de que, sob os parâmetros atuais, o contexto atual de racismo ambiental e sistêmico vem se dando de modo tal que não podemos ter a certeza de que um estado de alteração possa acabá-lo, mas que podemos assumir a sua estruturalidade para com ela reconhecer a necessidade de uma bioética alterativa da justiça.
Este trabalho situa os referentes da bioética e do genocídio sob dois aspectos de surgimento particulares, articulados entre si. Para a bioética, sua relação original com a produção de experimentos que repetiam as práticas dos cientistas alemães do regime nazista no berço intelectual e político do ocidente, que é os Estados Unidos da América (EUA). Para o genocídio, a sua conversão conceitual e política na tradução jurídica que resultou na Convenção para a Prevenção e Repressão do Crime de Genocídio, em 1948. Em minha argumentação, o enredamento desses dois acontecimentos, compartilhando de fundo os marcos de proteção dos direitos humanos, mantem consigo uma espécie de limitação de efeitos sob o uso e a delimitação conceitual desses referentes, que impede, por sua vez, a consciência de um amplo grau de devastação, no qual a presença real do genocídio e a ausência da bioética figuram em um mesmo plano político e concorrente para a persistência dessa realidade.

O trabalho se vale de referências críticas intelectuais dos estudos descoloniais, mas se vale em particular dos referenciais teóricos do pensamento intelectual negros e dos estudos críticos da raça. Essas referências não se reduzem e reproduzem integralmente como uma categoria intelectual homogênea e, menos ainda, unitária. Mas compartilham um direcionamento crítico importante para a realidade, recomposto de uma perspectiva de alteração proveitoso, situado sob as fronteiras das categorias analíticas tais como elas são praticadas (MOHANTY, 2003), entre dicotomi- 
zações e reduções sob o império da lei das instituições epistêmicas da modernidade do ocidente.

As inspirações teóricas desse trabalho também compartilham uma perspectiva crítica da racialidade e de sua articulação imperial entre a modernidade e o colonialismo, como sugerem as formulações teóricas de Aníbal Quijano (2005), acerca da colonialidade do poder. De modo particular também, essas referências intelectuais reconhecem o racismo como conformação reflexa de um projeto epistêmico mais amplo de modernidade, cuja violência operante carrega consigo uma lógica de repressão e hierarquização das diferenças. As implicações bioéticas interrogadas pela realidade histórica e persistente de um genocídio racializado são assim dispostas em perspectiva como produto de uma dinâmica dos modelos de conhecimento e de poder dominantes, nas quais o genocídio da população negra é paradigmático na compreensão da ameaça da colonialidade e do racismo a vários contextos e experiências de subalternização cultural de pessoas, cujas existências e corpos não se conformam às esquematizações universais de sujeito propostas sob o olhar do ocidente.

\section{BIOÉTICA E GENOCÍDIO: CONTEXTOS}

A bioética em seu surgimento nos EUA remete aos escândalos envolvendo pesquisas com seres humanos. Os experimentos começaram a ser denunciados ao longo dos anos 1960 como parte de uma tendência que surgia no pós-segunda guerra mundial, crítica da racionalidade dominadora da ciência e dos imperialismos na Europa e nos EUA, com pressões de atores sociais organizados por direitos civis, intelectuais e da comunidade científica.

Os experimentos, pontuados em escândalos sucessivos, remontam a práticas sistemáticas e toleradas no circuito de pesquisadores e profissionais biomédicos há muitos anos, e envolviam a realização de pesquisas sem o consentimento informado para o emprego de técnicas sem benefícios previstos e muitas vezes prejudiciais às participantes, além de uma preferência por grupos em contextos de grande vulnerabilidade: idosos, crianças, pessoas com deficiência intelectual ou transtorno mental, pessoas pobres e negras, até mesmo recém-nascidos.

À época em que esses escândalos nas pesquisas clínicas envolvendo pessoas surgiram, um profundo mal-estar foi gerado, diante da lembrança de que os incidentes suscitaram das práticas dos cientistas alemães nazistas na condução de experimentos no contexto do Holocausto. Com efeito, era profundamente desestabilizante a possibilidade de que os marcos normativos instituídos no pós-guerra e o repúdio à negação do direito à vida de grupos humanos não garantissem a repressão às práticas de desumanização e depreciação da dignidade de pessoas, e ainda mais que atos de tal gravidade se sugerissem no interior de uma nação autoproclamada defensora dos valores liberais e democráticos como os EUA. Apropriados do espírito do iluminismo e da civilização, os cientistas e a comunidade implicada no progresso científico da sociedade 
norte-americana não se viam sob os mesmos parâmetros de controle ético das atrocidades dos cientistas alemães.

Assim, a bioética também se constituiu em torno da produção de parâmetros éticos que dessem alcance à regulação dessa "boa ciência", que parecia paradoxalmente incapaz de coibir condutas inapropriadas exatamente por sua radical abjeção aos atos perpetrados no nazismo. Levando em conta as cifras crescentes investidas em pesquisas biomédicas nos EUA no pós-guerra e no contexto da guerra fria, as diretrizes institucionais da bioética e seus debates se deram também na necessidade de uma delicada ponderação entre a proteção dos interesses econômicos e científicos e a proteção da autonomia dos sujeitos participantes das pesquisas biomédicas financiadas.

Se, por um lado, as pesquisas biomédicas envolvendo pessoas geravam importantes benefícios à sociedade moderna e, em muitos casos, às pessoas participantes das pesquisas, muitas descobertas, por outro lado, se deram sob a produção de riscos e sob a questionável exploração de sujeitos cujas condições limitadas de autonomia e de acesso a recursos materiais e simbólicos diversos para sobrevivência permitiram benefícios ao círculos de empreendedores políticos e científicos das pesquisas envolvendo seres humanos, em prejuízo dos que participaram delas. Sob o paradigma do avanço científico e da concorrência econômica vigentes no campo político das pesquisas de então, o controle sobre a exploração da vulnerabilidade de determinados grupos para a satisfação do interes- se e das necessidades de outros foi o elemento disparador da bioética e do campo possível de mediações que pudessem democratizar o autoritarismo médico e corporativo na relação com sujeitos ditos vulneráveis, afastando a condescendência com condutas antiéticas e nazistas e, ao mesmo tempo, regulamentando as atividades e interesses clínicos, científicos e político-econômicos na pesquisa biomédica.

A consolidação da preocupação com a vulnerabilidade dos sujeitos no campo da bioética pode ser observada de forma reflexa na proteção jurídica que passou a ser conferida aos grupos vulneráveis no contexto dos direitos humanos, tendo também como referência o marco do desastre dos crimes do nazismo. Sem prejuízo dos inúmeros institutos de proteção aos direitos humanos de grupos específicos, o passado das violações desse funesto evento histórico é particularmente evocado no plano internacional sob o repúdio ao crime de genocídio, que sinaliza a proteção às garantias de sobrevivência material de coletividades vulneráveis à ação de grupos e poderes institucionalizados dominantes. Dispostos lado a lado, nesse sentido, os referenciais dos direitos humanos na bioética e na criminalização das práticas de genocídio conferem o horizonte de possibilidades de proteção de grupos contra a produção de práticas antiéticas que incorram na repetição do assujeitamento e do extermínio.

Esses marcos não interromperam, no entanto, a violência institucional contra a vida. No campo da bioética, muitas contribuições críticas vêm observando 
negligências éticas persistentes no desenvolvimento de pesquisas contemporâneas conduzidas por países desenvolvidos e corporações transnacionais com populações vulneráveis em países subdesenvolvidos, sobretudo na América Latina, na África e na Ásia. No Brasil, por sua vez, segue-se um histórico crescente de mortes violentas a cada ano. Segundo os dados do IPEA, foram registrados 62.517 homicídios em 2016, dos quais $71,5 \%$ tiveram por vítima pessoas negras (pretas e pardas), número que cresceu em 23,1\% no período de uma década, enquanto o restante da população teria tido uma redução dentre as vítimas de mortes violentas no percentual de 6,8\% (IPEA, 2018). Tal número, seguido de condições variadas de acesso limitado a dispositivos de garantia de dignidade e reconhecimento para esse segmento (cf. BRASIL, 2013; Werneck; Batista e Lopes, 2012), vem caracterizando um amplo e perpetuado genocídio contra a população negra (Nascimento, 1978; Carneiro, 2005; Reis, 2013).

Apesar da materialidade da persistência de uma dinâmica estrutural desigual e de processos de extermínio correntes contra grandes segmentos minorizados como a população negra no Brasil, a bioética e o genocídio seguem sendo operados como categorias delimitadas, adstritas à aplicação casuística e individual, através das quais essa realidade, suplementar e dolorosa, é afastada e mesmo negada pelas comunidades políticas de atores sociais nos quais a bioética e os direitos humanos da proteção de grupos vulneráveis se constituem como campo. Mas como esses campos se constituíram em definir e operar as categorias conceituais da bioética e do genocídio e sob que fronteiras essas categorias lidam com as realidades desiguais e de extermínio existentes? A seguir, retomo, em caráter exploratório, os episódios de surgimento e institucionalização desses campos em face das pressões e agenciamentos políticos e econômicos da colonialidade e do racismo.

\section{APROXIMANDO OS ANTE- CEDENTES DA BIOÉTICA E O GENOCÍDIO}

O surgimento da bioética nos EUA como campo remete ao mal-estar da comunidade científica e das instituições governamentais dos anos 60 e 70 em estabelecer novos parâmetros de controle sobre a pesquisa e a prática clínica biomédica diante de procedimentos e experimentos humanos que passaram a ser colocados sob suspeita de suas condutas éticas. No âmbito da comunidade acadêmica, faz parte dos marcos desse mal-estar a publicação de Henry Beecher que, em seu Ethics and Clinical Research, em 1966, denunciou pesquisas cujos protocolos colocavam em questão o respeito à dignidade e à autonomia das pessoas participantes.

Beecher encontrou condutas antiéticas que se repetiam entre vários trabalhos publicados e, conforme sustentava em seu artigo, circulavam entre as mais variadas instituições de pesquisas clínicas envolvendo seres humanos: pessoas doentes cujo tratamento efetivo era negado sem seu conhecimento; recurso a terapias químicas e técnicas de indução 
em pessoas saudáveis ou incapacitadas para teste de possíveis efeitos adversos - seguidos do acompanhamento de sérios danos às participantes, até a aplicação injustificada de técnicas para a verificação de disfunções, como uso tóxico de substâncias e superexposição a raios-x. Além dos recursos e meios empregados sistematicamente em prejuízo das participantes, as pesquisas relatadas guardavam ainda uma preferência constrangedora por doentes mentais, pacientes crônicos em estágios críticos de avanço cujas condições substanciais de escolha pela participação ou não nos experimentos eram bastante duvidosas, muitas delas inexistentes.

Das denúncias de Beecher à mobilização institucional e discursiva da bioética como campo, no entanto, precipitou o conhecimento de uma série de incidentes éticos semelhantes, envolvendo a comunidade científica e agências governamentais norte-americanas: a participação não consentida de 22 portadores de doenças crônicas em estado de senilidade em experimentos de injeção de células cancerígenas no Hospital Judaico de Nova Iorque, entre os anos de 1963 e 1966; a utilização de 800 crianças institucionalizadas com deficiência mental em um experimento de inoculação do agente causador hepatite viral para observação do desenvolvimento da doença, entre os anos de 1956 e 1970 (Hogemann 2015); e, ainda, o que ficou marcado nos precedentes da bioética como o caso Tuskegee (1932-1972), a história de 40 anos de 600 homens negros acompanhados pelo serviço médico local de sua cida- de, no Alabama, sem administração de diagnóstico ou tratamento algum e, consequentemente, sem qualquer consentimento informado das participantes. Sob o propósito de acompanhar o desenvolvimento da sífilis entre homens negros doentes e os comparando com outros saudáveis, as pessoas foram examinadas e sistematicamente iludidas de que estariam sendo tratadas de uma doença qualquer - a que chamavam de sangue ruim. O caso marcou de modo particular os precedentes da bioética pela continuidade do estudo, mantendo-se a observação do avanço da doença sobre os pacientes doentes até a morte de muitos deles, mesmo após a descoberta de um tratamento eficaz para a sífilis, por meio da administração de uma única dose de penicilina.

Em 1974, a emergência dos três escândalos citados, associados com o financiamento e o conhecimento da agência de pesquisa norte-americana (O National Institute of Health - NIH), deu impulso à consolidação institucional de diretrizes de controle e construção de parâmetros éticos para a revisão das pesquisas científicas financiadas pelo governo, que se deram com a padronização do sistema de revisão ética de pesquisa e com os princípios éticos eleitos no Relatório Belmont (Passini e Barchifontaine 2007).

Esse momento é considerado um importante marco na constituição da bioética no campo acadêmico, pressionando pela democratização dos critérios de justificação das pesquisas e intervenções clínicas com pessoas e mobilizando a entrada de interlocuto- 
res acadêmicos de outras disciplinas, a exemplo da Filosofia e da Teologia, e de outros atores sociais organizados no debate sobre o controle ético das ações médicas, então marcadas por um paternalismo médico evocado sob o ficou sendo o jargão bioético da ética à beira do leito (ethics at the bedside) (Rothman apud Diniz e Guilhem 2002).

Ora, esse paternalismo biomédico era respaldado por uma benevolência seguida da autoridade (paterna, afinal) que permitiu afastar até então a suspeita sobre suas ações. Subjacente aos acontecimentos que deram enlevo à constituição da bioética como campo, havia o mal-estar da comunidade científica e do Estado norte-americano de que as violações ao Código de Nuremberg (1947) - criado a partir da condenação de cientistas alemães pela prática de experimentos letais com prisioneiros - os colocassem sob o mesmo repúdio legado aos agentes do nazismo.

As regras do código preconizavam o respeito à vontade expressa pela participante como condição para realização e continuidade dos experimentos e estabeleciam a vedação sobre métodos e técnicas que pudessem resultar em danos, invalidez e morte das participantes. As inovações do código foram importantes precedentes à bioética, complementando o juramento hipocrático da defesa da vida na ética médica com a necessidade de observância e respeito à vontade expressa das participantes (Alves e Tubino 2006). Os pesquisadores estadunidenses da época, no entanto, desconsideravam a aplicação de tais regras, guardada sua relação com as atrocidades cometidas pelos cientistas alemães no Holocausto.

Tal como o Código de Nuremberg, a experiência ocidental terrificante do Holocausto motivou a tipificação do crime internacional de genocídio, por meio da Convenção para a Prevenção e Repressão do Crime de Genocídio, em 1948, cujo tipo penal repreendia a prática de extermínio de grupos por motivações nacionais, étnico-raciais ou religiosas:

Considerando que a Assembleia Geral da Organização das Nações Unidas, na sua Resolução n. ${ }^{\circ} 96$ (I), de 11 de Dezembro de 1946, declarou que o genocídio é um crime de direito dos povos, que está em contradição com o espírito e os fins das Nações Unidas e é condenado por todo o mundo civilizado; Reconhecendo que em todos os periodos da história o genocídio causou grandes perdas à humanidade; Convencidas de que, para libertar a humanidade de um flagelo tão odioso, é necessária a cooperação internacional; Acordam no seguinte: Artigo 1. ${ }^{\circ}$ As Partes Contratantes confirmam que $\mathrm{O}$ genocídio, seja cometido em tempo de paz ou em tempo de guerra, é um crime do direito dos povos, que desde já se comprometem a prevenir e a punir. Artigo $2 .^{\circ} \mathrm{Na}$ presente Convenção, entende-se por genocídio os atos abaixo indicados, cometidos com a intenção de destruir, no todo ou em parte, um grupo nacional, étnico, racial ou religioso, tais como: a) Assassinato de membros do grupo; b) Atentado grave à integridade física e mental de membros do grupo; c) Submissão deliberada do grupo a 
condições de existência que acarretarão a sua destruição física, total ou parcial; d) Medidas destinadas a impedir os nascimentos no seio do grupo; e) Transferência forçada das crianças do grupo para outro grupo. Artigo 3. ${ }^{\circ}$ Serão punidos os seguintes atos: a) O genocídio; b) $\mathrm{O}$ acordo com vista a cometer genocídio; c) O incitamento, direto e público, ao genocídio; d) A tentativa de genocídio; e) A cumplicidade no genocídio. (ONU, Convenção para a Prevenção e Repressão do Crime de Genocídio) ${ }^{1}$

Embora sua tipificação tenha se dado como uma resposta consensualmente assentida em repúdio às atrocidades cometidas pelo nazismo alemão, a confecção do texto normativo foi objeto de tensões entre os interesses dos Estados-nação de práticas imperiais e colonizatórias.

Em seu As fronteiras raciais do genocídio (2014), Ana Flauzina demonstra como o conceito teria passado à época por importantes agenciamentos de interesse dos EUA e da União Soviética na Assembleia Geral da Organização das Nações Unidas (ONU), no sentido de reduzir o genocídio ao extermínio físico intencional e objetivo, e de afastar a abrangência do crime a práticas de genocídio cultural e ao atentado contra grupos políticos e sociais, presentes na sua formulação original, de Raphael Lemkin:

o genocídio não significa necessariamente a destruição imediata de uma nação, exceto quando materializado por assassinatos em massa de todos os membros de uma nação. Significa a configuração de um plano coordenado de diferentes ações que visam à destruição dos fundamentos essenciais da vida de grupos nacionais, com o objetivo de aniquilar os grupos. Os objetivos de tal plano seriam a desintegração das instituições políticas e sociais, da cultura, da língua, dos sentimentos nacionais, da religião e da existência econômica de grupos nacionais, e a destruição da segurança pessoal, liberdade, saúde, dignidade, e até mesmo da vida dos indivíduos pertencentes a esses grupos. (Lemkin apud Flauzina 2016, p.123)

Especialmente para os EUA, o grande receio era de que fossem também incriminados pelo tratamento reservado aos segmentos minorizados sob seu território, a exemplo do flagrante descaso à sobrevivência de suas populações indígenas ao massacre de constituição de seu território e da vigência das leis segregacionistas contra a população afro-americana, que seguiriam oficialmente até 1965. Pensando das disputas em torno do significado jurídico e político do genocídio, os incidentes que precipitam a mobilização do campo da bioética nos EUA se sobrepõem à delicada disputa entre o reconhecimento e a negação do assujeitamento e do extermínio de populações vulneráveis no interior das narrativas da modernidade e do ocidente.

$\mathrm{Na}$ representação simbólica do Holocausto, que marca também a instituição do crime de genocídio, Flauzina destaca as implicações políticas que a sustentação de sua singularidade no evento do nazismo impõe ao reconhecimento de outras violações his- 
tóricas e sistemáticas a outros grupos, em particular, o das populações negras no mundo. Além do percurso de deslocamento semântico do genocídio, simbolicamente identificado com o massacre físico, estaria também, subjacente a essa imagética do Holocausto, a dificuldade em reconhecer a replicação de experiências semelhantes do nazismo com os processos anteriores e subsequentes de colonização e de escravização de outros povos e minorias inferiorizadas, praticadas nos territórios e além-fronteiras dos impérios das civilizações modernas e desenvolvidas da Europa e, posteriormente, também dos EUA. Além do arquétipo da monstruosidade do genocídio das práticas nazistas, concorre para a invisibilidade dessa imbricação a casuística jurídico-penal, cujo efeito é fragmentar complexos problemas de justiça com um esgotamento formal e político de caracterizações e sanções entre culpados e vítimas delimitadas ${ }^{2}$. A implicação disso é a invisibilidade da conexão histórica e estrutural da tragédia da modernidade ocidental do Holocausto com as experiências de racialização do colonialismo precedentes, concorrentes e subsequentes ao evento histórico do nazismo. Dispondo a episteme moderna e ocidental da proteção dos direitos humanos em perspectiva, tal lógica deriva de uma concepção formalista e fragmentarizante de processos seriados e estruturais mais amplos que informam a delimitação restritiva de caracterização do(s) genocídio(s) e das condutas violentas sob escrutínio da bioética. O resultado é a produção de campos éticos e de justiça no con- trole da violência que se tornam incapazes de se contraporem às dinâmicas violentas perpetradas pela própria lógica de hierarquização, racialização, exploração e assujeitamento produzidas pela modernidade ocidental vigente.

Face ao colonialismo, nesse sentido, a bioética se desdobra normatizando valores aprendidos com o trágico nas experiências em pesquisa e nas violações à sobrevivência e à integridade de populações vulneráveis que são replicações da desumanização e do desvalor pela existência de populações diversas, destacadas da sobreposição de processos contínuos e dissimulados de genocídio. Tal constatação é sensível diante da persistência de violações e de tensionamentos éticos na relação entre os interesses políticos do conhecimento científico e as condições estruturais de sobrevivência de populações sistematicamente ameaçadas - no genocídio ora em foco, o da população negra, mas que se articula também às condições difíceis de sobrevivência de indígenas, mulheres e homens com deficiência e crianças e idosos dentre outros, atravessados pela hierarquia e pela estratificação produzidas na lógica política de conhecimento da modernidade colonial.

O controle ético sobre as pesquisas com sujeitos vulneráveis, nesse sentido, disfarça uma relação constrangedora com o genocídio proveniente da produção estrutural e sistemática da vulnerabilidade de populações assujeitadas à existência em uma realidade discriminatória e injusta, na qual a gravitação da bioética em torno das pesquisas envolvendo seres humanos é um limitador conceitual e semântico importante, 
e, à primeira vista, até mesmo comprometedor dos esforços para uma episteme ampliada da bioética em direção a proteção integral da vida de sujeitos vulneráveis. Apesar disso, o campo de debates sobre a ética nas pesquisas em direitos humanos deu continuidade à construção de diretrizes institucionais e de reflexões críticas importantes através das quais a bioética vem ampliando o seu campo de significação e, com ele, suas possibilidades de transformação. $\mathrm{Na}$ parte desse trabalho que se segue, dou continuidade ao desdobramento de alguns dos marcos institucionais e paradigmas consolidados no campo da ética em pesquisa e das contribuições críticas teóricas da bioética voltadas a abordagens mais sensíveis às realidades persistentes de grupos minorizados e de nações e continentes inscritos sob o subdesenvolvimento.

\section{DELIMITAÇÕES INSTITUCIONAIS E NORMATIZAÇÕES DA BIOÉTICA EM UM MUNDO DESIGUAL}

De volta aos marcos de surgimento da bioética, os incidentes ocorridos nos EUA renderam um esforço de regulamentação suplementar das atividades em intervenção e pesquisa médicas. Com os escândalos envolvendo a exploração da vulnerabilidade de pessoas negras, crianças, pessoas com deficiência e prisioneiros na economia das pesquisas de doenças e testes de terapias, medicamentos e procedimentos de manipulação dos processos vitais e de adoecimento, ficaram patentes a insuficiência dos marcos regulatórios éticos profissionais, dos direitos huma- nos e a presunção da responsabilidade ética dos pesquisadores e profissionais de saúde na avaliação de seus próprios procedimentos. Cruciais no advento da bioética, essa consciência rendeu, com a Convenção de Helsinque, em 1964, e o Relatório de Belmont, em 1979, a delimitação de diretrizes institucionais especificamente voltadas à orientação e controle dos procedimentos biomédicos, dentre os quais a pesquisa assumiu grande importância, destacando a necessidade do respeito à autonomia, à integridade e à proteção das participantes das pesquisas frente aos interesses de conhecimento biomédico.

Do Relatório Belmont, nos EUA, produto da atividade da Comissão Nacional para a Proteção de Sujeitos Humanos na Pesquisa Biomédica e Comportamental, surgiu a tradição ética principialista no campo, que é ainda hoje influente nas discussões da ética biomédica (Diniz e Guilhem 2002). Os três princípios formulados no relatório, o da autonomia, da beneficência e da justiça, sofreram modulações e foram objeto de muitas críticas ao longo dos debates acumulados na história da bioética, mas tiveram o mérito de consolidar a observância pelos pesquisadores: da necessidade de um consentimento informado para a participação nas pesquisas; do compromisso com o bem-estar das pessoas participantes; e de que empreendimentos de pesquisa favorecidos por condições desiguais ou particularmente vulneráveis de seus sujeitos eram eticamente injustas sem benefícios da pesquisa para esses sujeitos que prezassem pelo alcance de certa equidade. 
Criada pela Associação Médica Mundial, a Convenção de Helsinque, por sua vez, foi um importante marco de referência para as pesquisas em âmbito internacional na proteção contra riscos de danos sérios ou irreversíveis às participantes e na garantia de retornos em benefícios nos tratamentos e resultados obtidos, limitando a justificação de pesquisas cujo controle de risco e a perspectiva de resultados positivos para as populações participantes não pudessem ser observados. Em particular também, a Convenção de Helsinque logrou consolidar o sistema de revisão ética das pesquisas envolvendo pessoas e a padronização dos parâmetros éticos locais das pesquisas ao nível internacional.

Esses marcos de diretrizes internacionais, vale notar, não foram os únicos, mas ofereceram as bases do que seria a influência paradigmática do principialismo ético na orientação dos procedimentos em pesquisa e na instituição dos sistemas de revisão ética dos procedimentos de pesquisa envolvendo seres humanos em âmbito internacional. Essas características demarcadoras do campo da bioética e de suas diretrizes regulatórias influenciaram de modo determinante os parâmetros de regulação da ética em pesquisa no Brasil ${ }^{3}$ e que conferiram estabilidade à identidade particular do termo bioética com a ética em pesquisa e, em particular, com os parâmetros biomédicos de avaliação ética dos procedimentos científicos com seres humanos.

Essas características demarcam o campo de conflitos e disputas na bioética contemporânea debatida no Brasil e na
América Latina, e que remetem à persistência de iniquidades e de problemas éticos no tratamento de sujeitos vulneráveis dentro e para além do campo das pesquisas biomédicas dentro das quais o campo da bioética se consolidou. Nesse campo de debates, se encontram importantes críticas. Dentre muitas destas, no Brasil, se encontra a crítica da comunidade de pesquisadores sociais em saúde acerca dos critérios biomédicos e da concepção genérica e universalizante dos valores ocidentais e eurocentrados contidos nas abordagens principialistas (Diniz e Guilhem 2002; Shuch e Víctora 2015; Fonseca 2015). No campo de contribuições teóricas latino-americanas inspiradas na crítica das teorias da dependência e do subdesenvolvimento, a chamada bioética de intervenção denunciou a persistência de desigualdades, os duplos padrões éticos, no compartilhamento dos retornos e no controle sobre os riscos a que populações vulneráveis nos países subdesenvolvidos são submetidas em pesquisas multicêntricas capitaneadas por empresas transnacionais e fundos de pesquisa de países desenvolvidos; e aos problemas decorrentes da redução da bioética - e da ética a ela subjacente - aos parâmetros e preceitos de controle de projetos e empreendimentos biomédicos, para efeito da regulamentação das atividades relacionadas à pesquisa social em saúde e da incidência da bioética sobre fenômenos éticos mais amplos relacionados à construção da vulnerabilidade e à garantia da proteção aos direitos humanos. (Garrafa 2009; Garrafa e Lorenzo 2009; Kottow 2008; Costa 2008). 
O mérito dessas contribuições críticas, tomadas na sua heterogeneidade e na multiplicidade de suas vozes no campo da bioética, foi principalmente o de abrir espaço à interpelação dissidente sobre os consensos institucionais firmados [no hemisfério norte, no eixo superior do ocidente] diante da persistência estrutural das injustiças e dos desafios à consolidação de práticas éticas com pessoas em um mundo culturalmente diversificado e também desigual. De modo subjacente também, essas confrontações críticas transbordam e desestabilizam as matrizes compreensivas restritivas e dominantes da bioética, em direção à compreensões críticas mais amplas e acuradas das correlações transversais entre os problemas da bioética (da vida) e as complexidades suscitadas pelas distintas formas de encarnar a vulnerabilidade e as demandas específicas por proteção, levando em conta aspectos econômicos, geopolíticos e culturais vivenciados em corporeidades de dentro das quais a diferença se expressa.

No interior de uma bioética constituída para afastar a replicação de atrocidades cometidas contra a vida, esses tensionamentos críticos são importantes para expandir as possibilidades de reflexão da bioética para a consciência do complexo enredamento que o conhecimento, e a sua relação com a vida, com a vulnerabilidade, guarda com o político e com a história da constituição das diferenças entre as pessoas através das quais as hierarquias se transformam e se atualizam, nos horizontes em que se entrecruzam a bioética com as dinâmi- cas da biopolítica (cf. Arán e Peixoto Júnior 2007).

É por isso demais limitada uma bioética que se restrinja à ética na pesquisa e que se confunda com a ética biomédica para os propósitos de uma consciência responsável das vulnerabilidades daquelas pessoas que se pretende proteger ${ }^{4}$. Para países como os do continente latino-americano e africano, para as populações negras e indígenas, para pessoas deficientes e inscritas sob a pobreza ou sob variadas formas de privação de recursos materiais e simbólicos de acesso a direitos, a vulnerabilidade à exploração antiética de uma pesquisa pode ser apenas um dentre variados fluxos, muitas vezes sobrepostos de violências, e para as quais o risco à vida pode ser muitas vezes uma confrontação cotidiana, para o qual as políticas públicas locais ou os marcos internacionais dos direitos humanos muitas vezes não fizeram ou não fazem diferença. É sob esses vieses que os preceitos normativos universais dos países desenvolvidos se afastam das lutas cotidianas das populações inscritas sob a categoria da vulnerabilidade e da subalternidade, e que igualmente suas estratégias de compreensão não conferem inteligibilidade aos contextos de violação e de extermínio, bem como não oferecem recursos de autocrítica a sua própria participação na perpetuação desses contextos de subalternização e de violência.

Da bioética de volta à problemática da singularidade e do reconhecimento do genocídio,

Não é uma questão de contabilidade ou de vencedores e vencidos na ba- 
talha da minoria mais martirizada. Não é uma questão de vitimologia comparativa, mas de sobrevivência coletiva. A insistência na incomparabilidade e na "singularidade" do Holocausto nazista é precisamente o que proíbe a compreensão coletiva de genocídio como um fenômeno de "civilização" ocidental, não como uma série de eventos históricos reiterativos, cada um em seu próprio caminho "único". É o que inibe a nossa capacidade de nomear causas, antecipar os resultados e, acima de tudo, envolver-se em ação política e intelectual de enfrentamento diante de experiências contemporâneas (Lilian Friedberg apud FLAUZINA, cit, 133-4)

Flauzina destaca o quanto o genocídio vem sendo reivindicado por movimentos sociais diversos para qualificar as suas experiências de violação. A autora propõe analisar essas reivindicações não do ponto de vista de sua adequação às formalidades e requisitos incorporados à tipificação do crime previstos na convenção, mas do que essas reivindicações podem expressar do ponto de vista da experiência daquelas que a reivindicam. Nesse sentido, o que está subjacente a essa demanda é o reconhecimento da existência dos grupos reivindicantes, que pretendem o reconhecimento da humanidade de sua coletividade através da proteção jurídica e simbólica conferida pela constatação das ameaças às suas vidas por meio da condenação penal aos agentes imputados - comumente o estado pelo crime de genocídio.

Sim, valeria a pena estudar clinicamente, no pormenor, os itinerários de Hitler e do hitlerismo e revelar ao burguês muito distinto, muito humanista, muito cristão do século $\mathrm{XX}$ que traz em si um Hitler que se ignora, que Hitler vive nele, que $\mathrm{Hi}-$ tler é o seu demónio, que se o vitupera é por falta de lógica, que, no fundo, o que não perdoa a Hitler não é o crime em si, o crime contra o homem, não é a bumilhaşão do homem em si, é o crime contra o homem branco, a humilhação do homem branco e o ter aplicado à Europa processos colonialistas a que até aqui só os árabes da Argélia, os $<<$ coolies $>>$ da Índia e os negros de África estavam subordinados (CESAIRE, 1978, p.18)

Se, pelo Discurso sobre o Colonialismo de Aimé Cesaire, a argumentação é de que o Holocausto simbolizado por Hitler é o produto da indiferença do ocidente ao massacre sistemático inscrito sobre o colonialismo, o repúdio do genocídio sob a memória monstruosa do nazismo, na qual se assenta a gênese da tradição humanista ocidental contemporânea, mantém invisível a sua relação com a perpetuação do racismo e com a desumanização gestada na experiência de extermínio e de assujeitamento das humanidades renegadas pelo imperialismo cultural do ocidente. Se, na ética ocidental dos Direitos Humanos, a ruptura com a violação à dignidade de qualquer pessoa constitui uma relativização ameaçadora à existência de toda a humanidade, a negação do reconhecimento histórico do evento colonial é também a perpetuação dessa ameaça, no qual o genocídio renegado do passado colonial às populações indígenas nas Américas e nas Áfricas se 
repetem na persistência do racismo e da indiferença moral à desumanização de algumas pessoas em detrimento de outras na contemporaneidade, nas quais também a racialidade da lógica colonial, antes aplicada às populações indígenas, tradicionais e afrodescendentes, também se reproduz no tratamento desumanizante e assujeitador de homens e mulheres portadores de transtornos mentais e de doenças crônicas; de idosos e tantos outros para os quais a racialização pode ser o processo paradigmático de tratamento de sua própria invisibilidade ou silenciamento.

Os reflexos dessa desumanização se dão sobrepostos ao avanço das tecnologias e possibilidades de administração da vida e da morte no contemporâneo e se investem da biopolítica e da instrumentação da racionalidade tradicional do ocidente de modo contínuo com a soberania e com a autoridade dos Estados-nação, entrecruzando capitalismo, democracia e mobilizando referenciais de proteção da vulnerabilidade humana, como o da defesa da vida, em favor do poder de decidir sobre quem vive e quem morre; sobre como vive e sobre como morre; sobre o quanto vive e sobre quando morre; sobre em função de quem se vive e sobre em função de quem se morre ${ }^{5}$. Tal dinâmica informa tanto a indiferença do estado quanto às cifras de mortes praticadas entre sujeitos racializados por meio do extermínio direto, como a intervenção difusa de interesses políticos e econômicos sobre a vida de populações tradicionais e nativas e sobre a biodiversidade.

\section{CONSIDERAÇÕES FINAIS: DE VOLTA A UMA BIOÉTICA DE ALTERAÇÃo}

Uma bioética substancialmente protetora da vulnerabilidade da humanidade e de seus espaços de sobrevivência e reprodução social, na sua diversidade, não pode se abster da consciência de que seus marcos, diretrizes normativas e institutos de controle sobre a atividade de conhecimento estão inscritos sob um mundo profundamente desigual, de sujeitos destituídos de sua humanidade por uma moldura ocidental racializada em vários níveis, dos quais a colonização e o capitalismo hierarquiza e subclassifica as diferenças em oposição e em favor da sobreposição de um humanismo particularizado, eurocentrado, branco, masculino, logocêntrico, burguês, corporalmente sadio e sexualmente moralizado, que limita e põe sempre em questão a existência dos sujeitos inscritos fora desse marco zero de humanidade. Para além dele, a diversidade particular de cada ser humano ou coletividade não pode ser concebida fora de uma redução instrumental de sua compreensão, o que implica em ser definido sempre como um Outro, de identidade e autodeterminação sempre condicionada por esse parâmetro cultural ocidental de humanidade, um ser humano ou coletividade relativos, subalternidades ou, como argumenta Spivak (2010), subalternidades às quais não é consentido falarem por si mesmas. O anseio por uma bioética de alteração com que conclui o título desse trabalho reflete de que é preciso ser assumida a consciência de que os rumos da ação humana no mundo não pode perma- 
necer como está, com o respeito ético de que as vidas enegrecidas pela racialidade importam, e mediante os quais os modos de conceber a vida e a bioética precisam se descolonizar para romper o racismo paradigmático de seu modo de reger a vida. Descolonizar também implica em reconhecer a vida no seu sentido mais ampliado, o da proteção da biodiversidade em que vivem os humanos e os não-humanos. A proteção da biodiversidade do mundo vivo que o regime político e moral de modernidade vigente demonstra não valorizar, mas se auto corroer através da destruição dos diversos mundos no qual nos interdependemos.

Parte dos efeitos dessa dinâmica de destruição em que se desdobra o genocídio é o que a filósofa Sueli Carneiro (2005) intitulou de epistemicídio, que se refere à forma pela qual as matrizes e referencias intelectuais de um grupo e, de modo mais amplo, suas perspectivas de conhecimentos e saberes são arrancadas e reduzidas. Se, no epistemicídio, as formas de conhecimento são essencialmente hierarquizadas e desfiguradas pela racionalidade moderna vigente, descolonizar as perspectivas de conhecimento e suas matrizes de produção é um dos dispositivos fundamentais de reversão das ferramentas de assujeitamento e de mortificação constituídas sob a realidade atual. Começar, por isso, pela bioética é um bom caminho, e acho que ela se faz sugerindo iniciar escutando as alterações e desestabilizações produzidas pelo eco das referências intelectuais e epistemológicas fronteiriças, excêntricas e suprimidas pelos enquadramentos intelectuais informados pelo epistemicídio de que fala Sueli Carneiro.

No presente trabalho, me empenho em incorporar o diálogo com leituras de intelectuais críticas fronteiriças específicas, latino-americanas, com especial destaque de referências da literatura acadêmica nacional, mas também em particular com homens e mulheres negros. Com a necessária cautela nos recursos a categorias de pertencimento e essencialização do lugar de reflexão intelectual, dialogar e refletir sobre posições diversas das posições de conhecimento dominantes é uma dentre as várias possibilidades e estratégias para o empreendimento necessário da descolonização de nosso pensamento.

Mais do que um uso afirmativo das modelagens intelectuais diferidas (para usar uma terminologia derridiana), o diálogo com referências intelectuais alteradas são os possíveis caminhos de alteração do quadro através dos quais os subalternos não podem falar e não podem viver. Pensar sob outros referenciais, isto é, descolonizar o pensamento, é também alterar as condições mediante as quais os sujeitos e sujeitas hoje subalternizadas possam também alterar os termos éticos ora vigentes de proteção da nossa bioética, da nossa ecologia política e alterar arranjos e pactos seculares antiéticos da modernidade que regem nossa interdependência.

\section{NOTAS}

1 http://pfdc.pgr.mpf.mp.br/atuacao-e-conteudos-de-apoio/legislacao/segurancapublica/convenca....crime genocidio. pdf, acessado em 15/07/2018. 
${ }^{2}$ Lógica, aliás, derivada de uma narrativa penalógica ocidental típica dos maniqueísmos morais e expiatórios que envolvem a produção da verdade nas formas jurídicas penalógicas ocidentais. Nesse sentido, ver Foucault (2001).

${ }^{3} \mathrm{~A}$ discussão aqui traçada se restringe à análise dos marcos de surgimento e de consolidação da bioética como campo científico e institucional de relação com a proteção de pessoas vulneráveis face ao conflito sobre o reconhecimento de realidades e contextos persistentes de genocídio. Sob esse recorte, há o receio de que se tenha perdido um importante aprofundamento sobre os marcos institucionais consolidados em âmbito internacional e, especialmente, no Brasil, que é aqui sequer mencionado. Dentre os ilustres ausentes, cite-se aqui: as inúmeras modificações e acréscimos à Declaração de Helsinque, em suas versões de 1975, 1983, 1989, 1996, 2000, 2008 e 2013; as Diretrizes Éticas Internacionais para a Pesquisa Envolvendo Seres Humanos, produzidas em 1993 pelo Conselho para Organizações Internacionais de Ciências Médicas, em colaboração com a Organização Pan-Americana de Saúde (CIOMs/OPAS) e a Declaração Universal sobre Bioética e Direitos Humanos, de 2005. Em âmbito nacional, o Brasil tem a ética em pesquisas envolvendo seres humanos regulamentada pelo Conselho Nacional de Saúde, em consonância com as disposições internacionais, cujos marcos vigentes mais importantes são a Resolução CNS 466/2012 e a Resolução 510/2016.

${ }^{4}$ A referência aqui é ao desdobramento redutor da bioética à ética biomédica em pesquisas envolvendo seres humanos, a partir da contribuição de André Hellegers (19261979), por oposição à perspectiva de uma bioética implicada no debate sobre as intervenções técnicas contemporâneas sobre as perspectivas de existência e coexistência da humanidade, projeto mais amplo de compreensão do campo de Van Rensselear Potter (1971), que teria sido o primeiro médico a editar uma produção acadêmica nos EUA com o termo.

${ }^{5}$ Esta passagem é a redução de um longo desdobramento teórico das reapropriações críticas dos conceitos de estado de exceção e de biopoder pelo pensamento negro contemporâneo, e que deságuam nas formulações da necropolítica, de Achille Mbembe (2011), mas também na contundente narrativa de Entre o paraiso e o purgatório, de Eduardo Taddeo (2014).

\section{REFERÊNCIAS}

Alves, E.; Tubino, P. 2006. Ética na pesquisa em seres humanos. Rev Med Fameplac, 1:25-36.

Arán, M.; Peixoto Júnior, C. A. 2007. Vulnerabilidade e vida nua: bioética e biopolítica na atualidade. Revista de saúde pública. 41: 849-857.

Butler, J. 2015. Quadros de guerra: quando a vida épassivel de luto. Rio de Janeiro: Civilização Brasileira.

Carneiro, A. S. 2005. A construção do outro como não-ser como fundamento do ser. Tese de Doutorado. Pós-Graduação em Educação, Universidade de São Paulo, São Paulo.

Cesaire, A. 1978. Discurso sobre o Colonialismo. Lisboa: Sá da Costa.

Costa, S. 2008. O desafio da ética em pesquisa e da bioética, "in" Ética em pesquisa: temas globais. Debora Diniz, Andréa Sugai, Dirce Guilhem, Flávia Squinca (Organizadoras). Brasília : LetrasLivres : Editora UnB.

Das, V. 2011. O ato de testemunhar: violência, gênero e subjetividade. Cadernos Pagu, 37: 09-41.

Diniz, D.; Guilhem, D. 2002. O que é bioética. Brasiliense. 
Flauzina, A. L. P. 2016. As fronteiras raciais do genocídio. Revista de Direito da Universidade de Brasilia,1(1): 119-146.

Fonseca, C. 2015. Situando os comitês de ética em pesquisa: o sistema CEP (Brasil) em perspectiva. Horizontes antropológicos, 21(44): 333-369.

Garrafa, V.; Lorenzo, C. 2009. Helsinque 2008: redução de proteção e maximização de interesses privados. Revista da Associação Médica Brasileira, 55(5): 514-518.

Garrafa, V. 2009. Da bioética de princípios a uma bioética interventiva. Revista bioética, 13(1):125-134.

Hogemann, E.R., 2015. O Caso Willowbrook: As Escolhas Éticas À Luz Do Pensamento De Agnes Heller The Revista Brasileira de Direito Animal, 10(20):169-188.

Instituto de Pesquisas Econômicas Aplicadas. 2018. Atlas da Violência 2018. Rio de janeiro: IPEA.

Kottow, M. 2008. História da ética em pesquisa com seres humanos, In Ética em pesquisa: temas globais. Debora Diniz, Andréa Sugai, Dirce Guilhem, Flávia Squinca (Organizadoras). Brasília: LetrasLivres : Editora UnB: 53-86.

Mbembe, A. 2011. Necropolítica: seguido de Sobre el gobierno privado indirecto. Mexico: Melusina.

Mebembe, A. 2014. Crítica da Razão Negra. Lisboa: Editora Antígona.

Mohanty, C. T. 2005. Feminism without borders: Decolonizing theory, practicing solidarity. London: Duke University Press.

Nascimento, A. do. 1978. Genocídio do negro brasileiro, $O$ : processo de um racismo mascarado. 1. ed. Rio de Janeiro: Paz e Terra.

Passini, L.; Barchifontaine, C. de P de. 2007. Problemas atuais de Bioética, $8^{\mathrm{a}} \mathrm{ed}$. Revista e ampliada, São Paulo: Centro Universitário São Camilo: Loyola.
Potter, V. R. 1971. Bioethics: Bridge to the future. London: Prentice $\square$ Hall.

Quijano, A. 2005. Colonialidade do poder, eurocentrismo e América Latina, In.: A colonialidade do saber: eurocentrismo e ciências sociais. Perspectivas latino-americanas. Eduargo Lander (org). Coleção Sur Sur, Buenos Aires: CLASCO: 107:130

Reis, V. 2013. Atucaiados pelo Estado: as politicas de segurança pública implementadas nos bairros populares de Salvador e suas representações (1991-2001). Dissertação de Mestrado, Pós-Graduação em Ciências Sociais, Salvador

Schuch, P.; Víctora, C. 2015. Pesquisas envolvendo seres humanos: reflexões a partir da Antropologia Social. Physis: Revista de Saúde Coletiva, 25(3): 779-796.

Spivak, G. C. 2010. Pode o Subalterno Falar? Belo Horizonte: Editora UFMG.

Taddeo, E. 2014. Entre o paraíso e o purgatório, In A Fantástica Fábrica de Cadáveres. São Paulo. CD, vol.2, Faixa 3.

Werneck, J.; Batista, L. E.; Lopes, F. 2012. Saúde da população negra. Brasília: ABPN. 